\title{
An Image-Based Mobile Health App for Postdrainage Monitoring: Usability Study
}

Chien-Hung Liao ${ }^{1 *}$, MD, FACS, FICS; Yu-Tung Wu ${ }^{1 *}$, MD; Chi-Tung Cheng ${ }^{1}$, MD; Chun-Hsiang Ooyang ${ }^{1}$, MD; Shih-Ching Kang ${ }^{1}$, MD; Chih-Yuan Fu ${ }^{1}$, MD; Yu-Pao Hsu ${ }^{1}$, MD; Chi-Hsun Hsieh ${ }^{1}$, MD, PhD; Chih-Chi Chen ${ }^{2}$, MD

${ }_{1}^{1}$ Department of Trauma and Emergency Surgery, Linkou Chang Gung Memorial Hospital, Chang Gang University, Taoyaun, Taiwan

${ }^{2}$ Department of Physical Medicine and Rehabilitation, Linkou Chang Gung Memorial Hospital, Chang Gang University, Taoyaun, Taiwan

* these authors contributed equally

Corresponding Author:

Chih-Chi Chen, MD

Department of Physical Medicine and Rehabilitation

Linkou Chang Gung Memorial Hospital

Chang Gang University

5, Fuxin street, Kweishiang district

Taoyaun, 333

Taiwan

Phone: 88633281200 ext 3651

Email: Claudia5477@gmail.com

\section{Abstract}

Background: The application of mobile health (mHealth) platforms to monitor recovery in the postdischarge period has increased in recent years. Despite widespread enthusiasm for mHealth, few studies have evaluated the usability and user experience of mHealth in patients with surgical drainage.

Objective: Our objectives were to (1) develop an image-based smartphone app, SurgCare, for postdrainage monitoring and (2) determine the feasibility and clinical value of the use of SurgCare by patients with drainage.

Methods: We enrolled 80 patients with biliary or peritoneal drainage in this study. A total of 50 patients were assigned to the SurgCare group, who recorded drainage monitoring data with the smartphone app; and 30 patients who manually recorded the data were assigned to the conventional group. The patients continued to record data until drain removal. The primary aim was to validate feasibility for the user, which was defined as the proportion of patients using each element of the system. Moreover, the secondary aim was to evaluate the association of compliance with SurgCare and the occurrence of unexpected events.

Results: The average submission duration was 14.98 days, and the overall daily submission rate was $84.2 \%$. The average system usability scale was 83.7 (SD 3.5). This system met the definition of "definitely feasible" in 34 patients, "possibly feasible" in 10 patients, and "not feasible" in 3 patients. We found that the occurrence rates of complications in the SurgCare group and the conventional group were $6 \%$ and $26 \%$, respectively, with statistically significant differences $P=.03$. The rate of unexpected hospital return was lower in the SurgCare group (6\%) than in the conventional groups $(26 \%)(P=.03)$.

Conclusions: Patients can learn to use a smartphone app for postdischarge drainage monitoring with high levels of user satisfaction. We also identified a high degree of compliance with app-based drainage-recording design features, which is an aspect of mHealth that can improve surgical care.

(J Med Internet Res 2020;22(8):e17686) doi: $\underline{\text { 10.2196/17686 }}$

\section{KEYWORDS}

telemedicine; smartphone; surgical drainage; postdrainage care, mHealth

\section{Introduction}

Surgical drainage is a therapeutic procedure with multiple purposes, including relieving symptoms, bypassing occlusions, and monitoring postoperative conditions [1-4]. In patients with acute biliary diseases, such as acute cholecystitis or cholangitis, drainage can relieve symptoms and stabilize the patient's condition [5-7]. Drainage can also postpone emergency surgery, undergoing interval surgery instead $[8,9]$. Sometimes, patients need to monitor their own drains because of a prolonged 
therapeutic course. Traditional postdischarge drainage care depends on medical professionals asking patients to record the amount and characteristics of the fluid drained. However, these self-report measures are not only unreliable in elderly adults and those with impaired cognition [10,11], but also time-consuming with regard to processing the data [12]. Inadequate monitoring and care might prolong drainage insertion, delay recovery, reduce quality of life, and induce sequential complications such as an electrolyte imbalance, dehydration, sepsis, or physical injury related to disruption of the drain placement $[13,14]$. Therefore, proper monitoring of the drainage status is a critical issue.

In the last decade, apps for mobile devices have radically changed modern lifestyles. Additionally, the healthcare sector has been enriched by numerous apps $[15,16]$. Because of the increase in popularity of this new technology, the World Health Organization (WHO) has defined these tools as electronic health (eHealth) and mobile health (mHealth) applications. As the ownership of mobile devices has become more common [17], patients and their caregivers are increasingly willing to use technology to access health care $[18,19]$. Several studies have demonstrated that mHealth technology improves the control of cardiac function and glycemic hemostasis, enhances medication compliance, and shortens hospital stays [20-24]. Additionally, prior research on app protocols for surgical patients has focused on routine procedures that already have a low baseline rate of postoperative and discharge complications [25-27]. Although the experience with using mHealth apps in surgical care is limited, it has been suggested that surgical patients benefit from this new technological mode of support [28,29].

We developed an internet-based remote app to monitor drainage and conducted a study to investigate the adequacy of the remote app with regard to helping patients and caregivers properly manage drains at home. This study focused on the feasibility and clinical value of the remote app for patients with percutaneous or surgical drainage.

\section{Methods}

\section{Study Population}

Patients who were eligible to participate in this study were adult inpatients (aged $\geq 20$ years) in the acute care surgery department of a medical center. We enrolled patients who were undergoing percutaneous or surgical drainage of the biliary tract or peritoneal cavity at our department from May 2019 to October 2019. All patients who fulfilled the inclusion criteria were approached to participate in this study. Notably, patients were excluded if they had neurologic or cognitive disorders prohibiting their usage of the app or ability to give informed consent. To calculate the sample size, we used the following parameters: $\alpha=.05$, a power of $80 \%$, an enrollment ratio of 1.6 , and a complication decreasing rate of $18 \%$. We recruited 50 patients to participate in the app group and 30 patients to participate in the conventional group.

The institutional review board of Chang Gung Memorial Hospital approved this study protocol (201900495B0). A research assistant helped the enrolled patients and caregivers install the app on their smartphones and instructed them how to use the app before the operation. Before patients were enrolled in this study, the research assistant evaluated their familiarity with wearable devices and smartphones. If the patients were not confident about using these devices, we provided further instructions to their caregivers.

\section{SurgCare App}

SurgCare (Figure 1) is an iOS/Android app that facilitates the recording of postprocedural clinical variables (drainage amount, discharge color, associated discomfort, body weight, and analgesic ingestion) by patients who have had drains placed.

The app transmits digital images of the surgical wound and drainage to the medical staff as shown in Figure 2.

SurgCare was developed by surgical professionals and software programmers to fulfill the needs of patients caring for drains at home and was only used by patients who were followed in our institute. Figure 3 presents the system architecture. Once the user inputs the data into the app, the information is synchronized with the server when internet access is available on the smartphone. This interdevice data transmission worked well, with no abnormal events reported by the patients.

Furthermore, the research assistant monitored the synchronizing of the data on weekdays and called the patients if their information was missing. If there was a change in fluid color, persistent changes in vital signs or abnormal drainage, this information was provided by smart devices to the medical doctors who then arranged further management. Patients continued to transmit data until their drains were removed. The research assistant did not have contact with the conventional group when patients were at home. Another medical staff member who did not participate in designing this system independently reviewed and analyzed the data. 
Figure 1. Screenshots of the SurgCare app showing the records of date, drain method, drainage amount, color, and image of drained material and wound status.

\section{$\times$ SurgCare}

\begin{tabular}{|l|l|l|l|l|l|l|}
\hline Dr. Hssocox & & & \\
\hline
\end{tabular}

Figure 2. Image of drainage-inserted wound and drainage content. A: wound with percutaneous gallbladder drainage; B: wound with percutaneous biliary drainage; C: yellowish bile drainage; D: mucus-like white bile drainage.

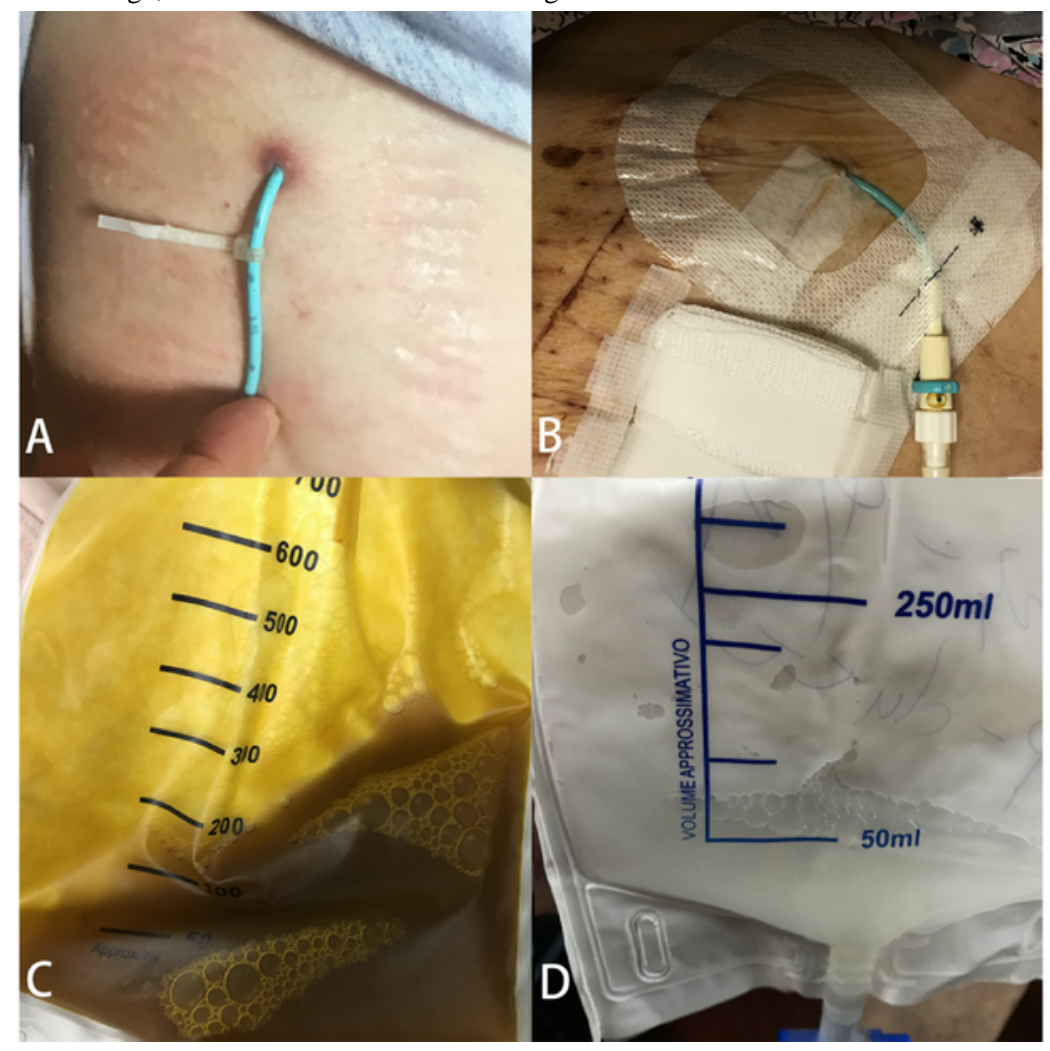


Figure 3. System architecture of the mobile device for recording postdrainage care.

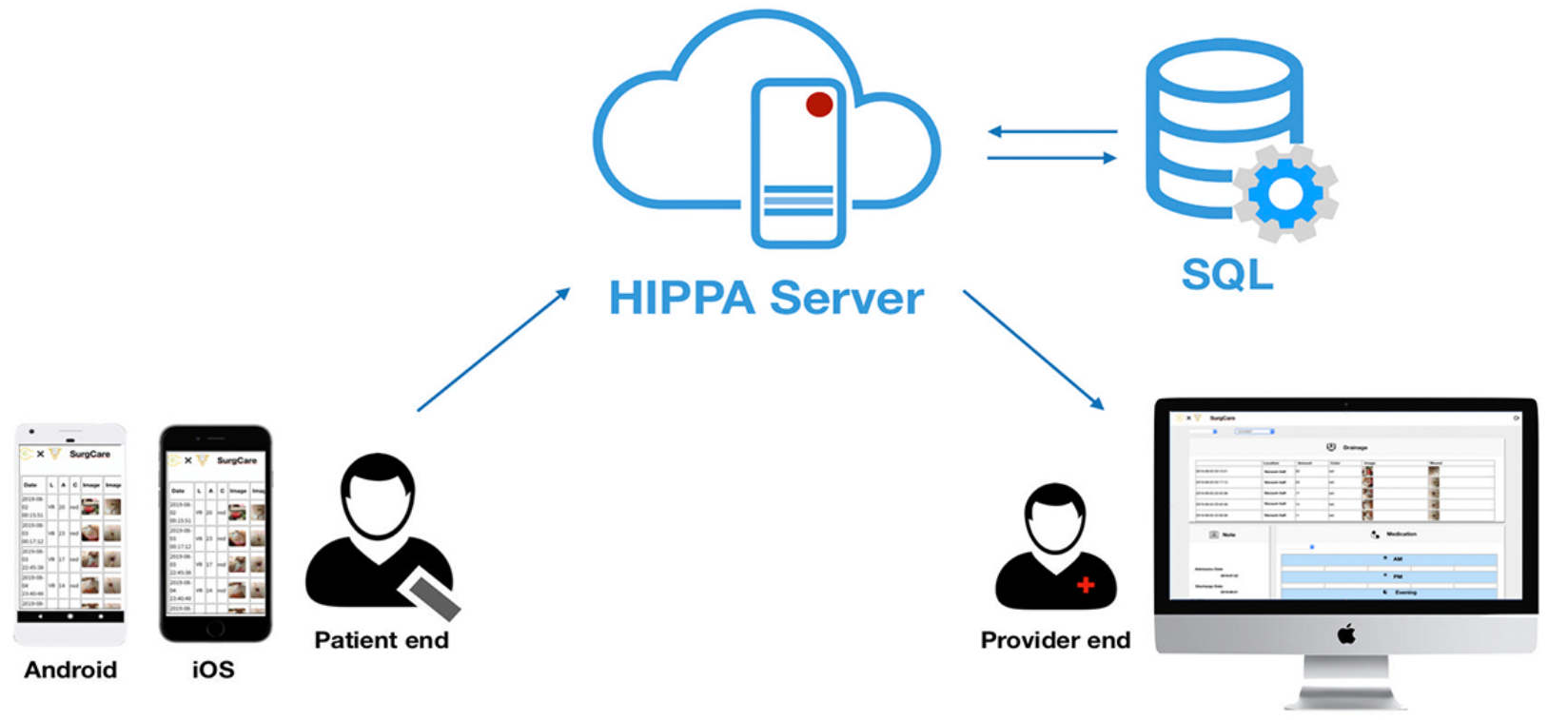

\section{User Tasks}

We formally tested the usability and feasibility of the app with postdischarge drainage patients at a major academic medical center. The app was loaded onto an iOS or Android smartphone or tablet. We assessed patients' baseline familiarity with smartphones prior to testing. User tasks included waking up the device, launching the app, inputting information (including drainage amount, color, and the presence of discomfort), capturing an image, reviewing and retaking or accepting captured images, responding to questions, and submitting the data.

\section{Measures and Analysis}

\section{Feasibility: Protocol Completion}

Following usability testing of the app, participants were asked to rate their performance and to provide feedback on the app. Participants also used a system usability scale to evaluate their satisfaction with the app [30].

We evaluated the compliance of the patients with the use of SurgCare. If patients submitted data on more than $80 \%$ of days on which they had a drain, they were classified in the good compliance group. If the number of days on which data were submitted was less than $80 \%$ of the total number of days for which they had the drains, we classified them in the poor compliance group.

In this study, the feasibility was assessed as in past studies [31]. The feasibility was defined as the proportion of participants using each element of the system for at least $70 \%$ of the period. "Definitely feasible," "possibly feasible," and "not feasible" were defined as $\geq 70 \%, 50 \%-69 \%$, and $<50 \%$ of the participants meeting that criterion, respectively.

\section{Clinical Value: Association of App Usage With Early Complication Rate}

The clinical outcome of interest was validation that the use of the app leads to fewer complications and a lower incidence of unexpected hospital return. We compared the high compliance group with the poor compliance group and conventional group with regard to the total compliance rate, incidence of drain dysfunction, incidence of drain dislodgement, and rate of infection. We also analyzed the rates of unexpected hospital return and readmission in these groups.

\section{Statistical Analysis}

Pearson's chi-square test and Fisher exact test were used to compare categorical variables. Quantitative variables were compared with Student's $t$ test. Levene's test was used to correct for intergroup variations before the application of Student's $t$ test. Statistical analysis was performed with SPSS v 20.0 for Macintosh (SPSS Inc). A value of $P<.05$ was considered statistically significant.

\section{Results}

\section{Participant Characteristics}

In total, 105 patients underwent 108 procedures during the study period. Out of these 105 patients, 3 patients with repeated procedures were excluded. After being approached, 8 patients refused to participate in this project, and another 14 patients had cognitive problems and were excluded from this study. Of the 80 patients who were approached, were eligible, and agreed to participate, 6 patients were lost to follow-up. A total of 47 participants completed the usability testing, 26 of whom had caregiver assistance or proxy participation. Another 27 patients were included in the conventional group; these patients used the traditional hand recording method to track the drainage amount and color. The study flow diagram is shown in Figure 4.

Demographics and basic clinical information of SurgCare group are presented in Table 1. The average duration of app use was 14.5 (SD 3.2) days. The common termination of follow-up was drainage removal and wound closure, followed by a lack of satisfaction and complications. 
Figure 4. Flow diagram of the study design.

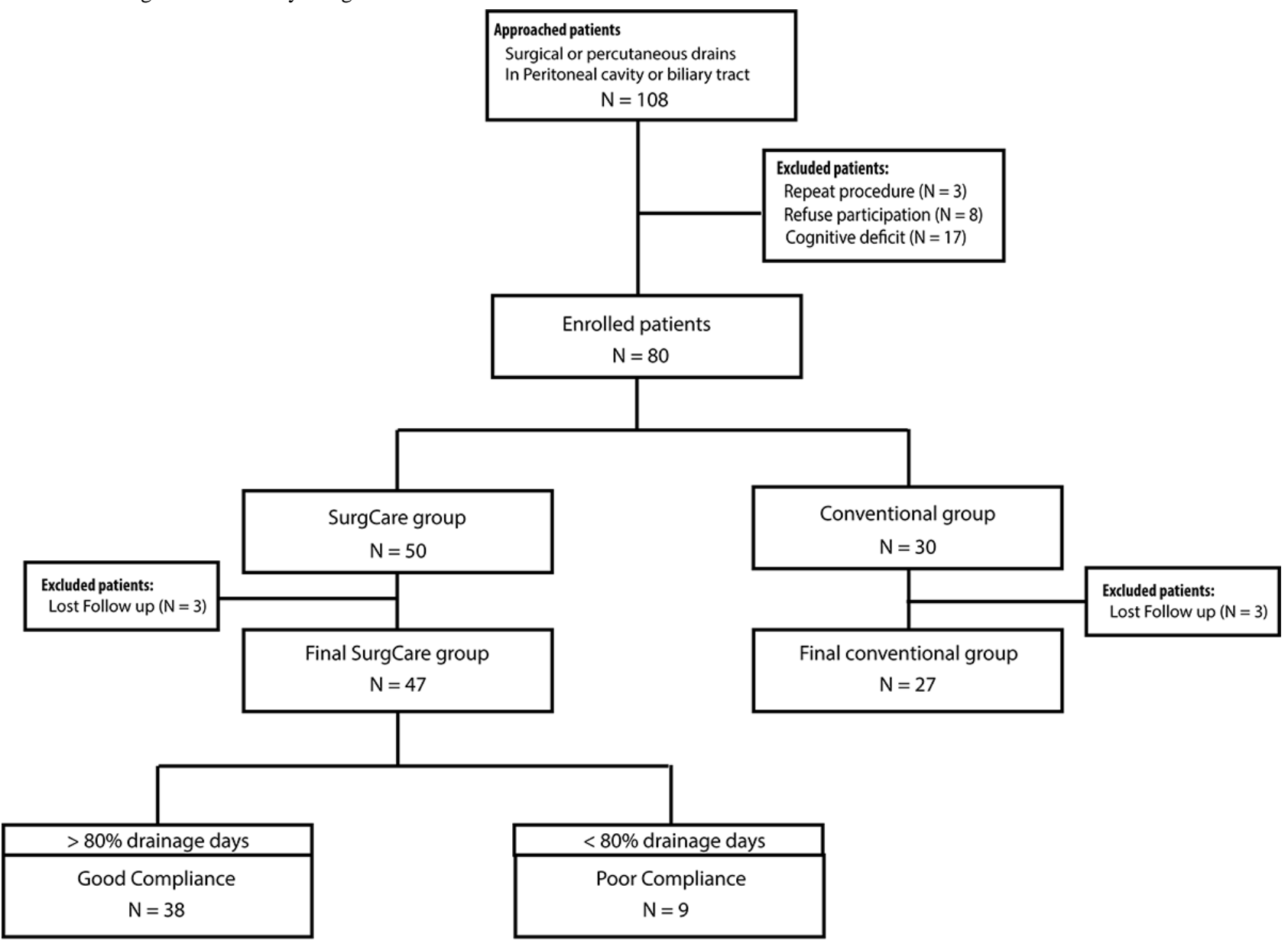


Table 1. Demographic characteristics of SurgCare participants with surgical and percutaneous drainage $(\mathrm{N}=47)$.

\begin{tabular}{|c|c|}
\hline Characteristics & Value \\
\hline Age, mean (SD) & $61.4(15.9)$ \\
\hline \multicolumn{2}{|l|}{ Gender, n (\%) } \\
\hline Male & $29(62)$ \\
\hline Female & $18(38)$ \\
\hline \multicolumn{2}{|l|}{ Underlying disease, $\mathrm{n}(\%)$} \\
\hline Hypertension & $21(45)$ \\
\hline Diabetes mellitus & $16(34)$ \\
\hline Renal insufficiency & $7(15)$ \\
\hline Chronic obstructive pulmonary disease & $3(6)$ \\
\hline Malignancy & $3(6)$ \\
\hline \multicolumn{2}{|l|}{ Drainage site, $\mathrm{n}(\%)$} \\
\hline Biliary drainage & $25(53)$ \\
\hline Peritoneal drainage & $22(47)$ \\
\hline \multicolumn{2}{|l|}{ Method of participation, $n(\%)$} \\
\hline Independent & $21(45)$ \\
\hline Caregivers & $26(55)$ \\
\hline System usability scale, mean (SD) & $83.7(3.5)$ \\
\hline \multicolumn{2}{|l|}{ Feasibility test, n (\%) } \\
\hline Definite feasible & $34(72)$ \\
\hline Possibly feasible & $10(21)$ \\
\hline Not feasible & $3(6)$ \\
\hline \multicolumn{2}{|l|}{ Overall daily compliance } \\
\hline Total drainage days, $\mathrm{N}$ & 836 \\
\hline Day submitted, n (\%) & $704(84)$ \\
\hline Day missed, n (\%) & $132(16)$ \\
\hline \multicolumn{2}{|l|}{ Complication, n (\%) } \\
\hline Dysfunction & $1(2)$ \\
\hline Dislodge & $0(0)$ \\
\hline Infection & $2(4)$ \\
\hline Unexpected return & $3(6)$ \\
\hline Unexpected readmission & $2(4)$ \\
\hline
\end{tabular}

To compare SurgCare group with the conventional group, we identified gender, age, underlying chronic disorders, drainage site, and method of participation for both the groups. Total occurrence of complication was lower in SurgCare group (6\%) than in the conventional group (26\%) with statistical significance of $P=.03$. The incidence of drainage dislodge was lower in
SurgCare group (2\%) than in the conventional group (11\%) with statistical significance of $P=.045$. Moreover, the unexpected hospital return was lower in SurgCare group $(6 \%)$ than in the conventional group (26\%) with significant difference of $P=.03$ (Table 2). 
Table 2. Comparison of the characteristics and prognosis of patients within the SurgCare and conventional groups.

\begin{tabular}{|c|c|c|c|}
\hline Characteristics & SurgCare & Conventional & $P$ value \\
\hline Patients, $\mathrm{n}$ & 47 & 27 & $-^{\mathrm{a}}$ \\
\hline Age, mean (SD) & $60.2(17.1)$ & $63.6(13.4)$ & .36 \\
\hline Gender, n (\%) & & & 60 \\
\hline Male & $29(62)$ & $15(56)$ & \\
\hline Female & $16(38)$ & $12(44)$ & \\
\hline \multicolumn{4}{|l|}{ Underlying disease, $n(\%)$} \\
\hline Hypertension & $21(45)$ & $8(30)$ & .23 \\
\hline Diabetes mellitus & $16(34)$ & $6(22)$ & .43 \\
\hline Renal insufficiency & $7(15)$ & $5(19)$ & .75 \\
\hline Chronic obstructive pulmonary disease & $3(6)$ & $2(7)$ & $>.99$ \\
\hline Malignancy & $3(6)$ & $3(11)$ & .66 \\
\hline Drainage site, $\mathrm{n}(\%)$ & & & .08 \\
\hline Biliary drainage & $25(53)$ & $20(74)$ & \\
\hline Peritoneal drainage & $22(47)$ & $7(26)$ & \\
\hline Method of participation, $n(\%)$ & & & .37 \\
\hline Independent & $21(45)$ & $15(56)$ & \\
\hline Caregivers & $26(55)$ & $12(44)$ & \\
\hline Complication, n (\%) & $3(6)$ & $7(26)$ & $.03^{\mathrm{b}}$ \\
\hline Dysfunction & $1(2)$ & $3(11)$ & .14 \\
\hline Dislodge & $0(0)$ & $3(11)$ & $.045^{\mathrm{b}}$ \\
\hline Infection & $2(4)$ & $1(4)$ & $>.99$ \\
\hline Unexpected hospital return & $3(6)$ & $7(26)$ & $.03^{\mathrm{b}}$ \\
\hline Unexpected readmission & $2(4)$ & $4(15)$ & .11 \\
\hline
\end{tabular}

${ }^{\mathrm{a}}$ Not applicable.

${ }^{\mathrm{b}}$ Fisher Exact test.

\section{Feasibility and Usability Evaluation of SurgCare}

After evaluation, there were 34 patients for whom it was definitely feasible to use this app. For 10 patients, use of the app might be feasible, although they needed more support from the research assistant to help them operate the system. Another 3 patients were in the infeasible group because they completed less than $30 \%$ of the elements. The overall system usability score for the app was 83.3, which is considered good in usability testing.

\section{Association of SurgCare App Usage Compliance and Early Complication Rate}

In the good compliance group, we found that the rate of complications related to drainage was $3 \%$, which was much lower than that in the poor compliance group (11\%). With regard to unexpected hospital return (3\% vs $11 \%$ ) and readmission ( $3 \%$ vs $11 \%$ ), the good compliance group had better results than the poor compliance group and the conventional group as shown in Table 3. 
Table 3. Comparison of the prognosis of patients with SurgCare with good and poor compliance.

\begin{tabular}{|c|c|c|c|}
\hline Characteristics & Good compliance & Poor compliance & $P$ value \\
\hline Patients, $\mathrm{n}$ & 38 & 9 & $-{ }^{\mathrm{a}}$ \\
\hline Age, mean (SD) & $60.3(18.1)$ & $60.0(13.1)$ & .96 \\
\hline Gender, n (\%) & & & .27 \\
\hline Male & $22(58)$ & $7(78)$ & \\
\hline Female & $16(42)$ & $2(22)$ & \\
\hline \multicolumn{4}{|l|}{ Underlying disease, $\mathbf{n}(\%)$} \\
\hline Hypertension & $16(42)$ & $5(56)$ & .47 \\
\hline Diabetes mellitus & $15(40)$ & $1(11)$ & .11 \\
\hline Renal insufficiency & $7(18)$ & $0(0)$ & .32 \\
\hline Chronic obstructive pulmonary disease & $1(3)$ & $2(22)$ & .09 \\
\hline Malignancy & $2(5)$ & $1(11)$ & .48 \\
\hline Drainage site, $\mathrm{n}(\%)$ & & & .87 \\
\hline Biliary drainage & $20(53)$ & $5(56)$ & \\
\hline Peritoneal drainage & $18(47)$ & $4(44)$ & \\
\hline Method of participation, $n(\%)$ & & & .14 \\
\hline Independent & $15(40)$ & $6(67)$ & \\
\hline Caregivers & $23(61)$ & $3(33)$ & \\
\hline \multicolumn{4}{|l|}{ Complication, n (\%) } \\
\hline Dysfunction & $1(3)$ & $0(0)$ & $>.99$ \\
\hline Dislodge & $0(0)$ & $0(0)$ & $>.99$ \\
\hline Infection & $1(3)$ & $1(11)$ & .32 \\
\hline Unexpected hospital return & $2(5)$ & $1(11)$ & .52 \\
\hline Unexpected readmission & $1(3)$ & $1(11)$ & .26 \\
\hline
\end{tabular}

${ }^{\mathrm{a}}$ Not applicable.

\section{Discussion}

This study demonstrated the feasibility of using a mobile app to monitor the recovery status of patients with drains and to assist patients and caregivers in detecting abnormalities in a timely manner. Remote apps could support self-care and allow close follow-up [32-34]. We also identified an unexpected reduction in the rates of hospital return and readmission in the SurgCare group $(6.4 \%)$ compared with the conventional group $(25.9 \%) \quad(P=.02)$. We found that the occurrences of complications such as dislodgement $(0 \%)$, infection $(4 \%)$, and dysfunction (2\%) were relatively fewer in the SurgCare group. To the best of our knowledge, this is one of the first innovative studies focusing on the development of comprehensive app functions to assist surgical patients with drain care and monitoring. With the evaluation of uploaded image of wound and drainage content, the health care team can identify the abnormalities earlier to prevent the sequential complications, which is one of the causes to reduce unexpected hospital return. The current standard of care for the majority of surgical patients following hospital discharge involves little formal communication between patients and their care team until their routine clinic follow-up 2-3 weeks after discharge [35,36]. Some
mHealth protocols have been developed to improve patient monitoring or replace routine postoperative clinic visits [37-39]. In addition to this trend, the national policy priority mandates improving transitions of care following hospital discharge and reducing hospital readmissions [40,41]. We created an image-based mobile app aimed at increasing communication between patients and health care personnel after discharge from the hospital as part of an effort to detect drainage complications in an early stage and reduce hospital readmissions.

The compliance with using apps is generally high. Apps for surgical patients must be developed carefully, keeping in mind that the users are very vulnerable $[42,43]$. In this study, we find that compliance with using the SurgCare was acceptable. Most participants found the app easy to use (\%), though the questions that did not elicit an unanimously positive response indicate that there is a degree of tentativeness regarding participants' ability to independently perform the functions in the SurgCare. The SurgCare can provide assistance not only by facilitating monitoring but also by providing psychological support [44,45]. For patients and caregivers who are not familiar with postoperative wound care, remote support helps them detect the early dislodgement or dysfunction of the drain, and it can reduce the subsequent occurrence of infections and other 
complications. Self-report questionnaires are the most common method of monitoring drainage because of their cost-effectiveness and ease of administration [46]. However, the disadvantages of self-report questionnaires include a lack of reliability and the influences of social desirability, age, questionnaire complexity, and recall ability [47,48]. Therefore, an easily used mobile app can solve these problems. With immediate recording and image capture, the app is an excellent tool for close monitoring. Moreover, SurgCare can offer a rapid response to help patients psychologically, as patients and caregivers can receive responses from healthcare personnel before returning to the clinic. The daily monitoring messages are delivered via mobile messaging (eg, short message service) instead of email to facilitate more immediate communication. These adjustments are expected to improve user satisfaction and compliance and may ultimately further enhance the efficacy of the intervention.

Furthermore, 4 key categories of age-related barriers are associated with the use of mHealth by older adults, namely, barriers related to cognition, motivation, physical ability, and perception [26]. As surgical drainage patients are usually older adults (median age $>60$ years) who have the potential to develop cognitive or memory impairments, it is crucial to select an easy-to-follow app to use in clinical research with this population. We noticed that if the patients were well trained, they were able to input their health data by themselves without any dependence on a physician's assistant, study nurse, or other caregivers $[49,50]$. After the interview, we also noticed that the surgeons were interested in the electronic assessment of patient-reported outcomes rather than the conventional manual reporting of the drainage amount and status. Previous studies have suggested that the electronic assessment of patient-reported outcomes was as accurate as the conventional method of manual recording [51,52]. Another survey of 108 health care personnel showed a high level of acceptance (84.3\%) of app-assisted recording [53]. Digital medicine is unstoppable, and patient empowerment plays a new and growing role in disease management. With support from both patients and health providers, we can determine the impact of mHealth on the postprocedural care of surgical drains.
In contrast to the generally rapid growth of mHealth in medical fields, research on surgical topics has been limited. Among studies focusing on the application of mHealth to surgical issues, several have investigated wound care and pain scaling to validate the clinical usefulness of mHealth [54-57]. A recent study used another wearable device to track the step counts of patients who had undergone various abdominal surgeries for 1 month after discharge and showed that the mHealth app could effectively track recovery [24,58]. Because drain care is an issue that is unique to surgical patients, and telephone conversations and questionnaires cannot be used to access the visual component. In this study, we developed an app that can improve compliance with postdischarge drainage care and monitoring and reduce the risk of drainage complications.

\section{Limitations}

This study had several limitations that should be considered when interpreting the results. First, all assessments were conducted online, and inclusion relied exclusively on self-reported data. Therefore, the internal validity and generalizability to a larger clinical population might have been compromised. Second, there was a rather low postassessment response rate. The lack of data from approximately one-fifth of the sample limits the validity of our findings since it remains unclear how satisfied the nonresponders were and how they differed in terms of symptomatology. Third, the sample size was limited, and the sample did not represent all surgical patients. Subsequent research should, therefore, investigate the efficacy and cost-effectiveness of SurgCare in a fully powered randomized control trial. The study provided valuable information about the feasibility and adequacy of an internet-based intervention for the management of drains, which can be used to guide subsequent research.

\section{Conclusion}

In this study, we present a remote app that can improve patient compliance with postdischarge drainage care and monitoring and reduce the rate of major complications. The patients were enthusiastic about partnering with their health providers in novel ways to optimize their healthcare. Although mHealth will certainly not replace physician contact, it will serve as a digital assistant for diagnostic, therapeutic, and follow-up purposes, supporting patient recovery.

\section{Conflicts of Interest}

None declared.

\section{References}

1. Kortram K, de Vries Reilingh TS, Wiezer MJ, van Ramshorst B, Boerma D. Percutaneous drainage for acute calculous cholecystitis. Surg Endosc 2011 Nov;25(11):3642-3646 [FREE Full text] [doi: 10.1007/s00464-011-1771-5] [Medline: 21638173]

2. Chousleb E, Szomstein S, Podkameni D, Soto F, Lomenzo E, Higa G, et al. Routine abdominal drains after laparoscopic Roux-en-Y gastric bypass: a retrospective review of 593 patients. Obes Surg 2004 Oct;14(9):1203-1207. [doi: 10.1381/0960892042387101] [Medline: 15527635]

3. Wallace MJ, Chin KW, Fletcher TB, Bakal CW, Cardella JF, Grassi CJ, Society of Interventional Radiology (SIR). Quality improvement guidelines for percutaneous drainage/aspiration of abscess and fluid collections. J Vasc Interv Radiol 2010 Apr;21(4):431-435. [doi: 10.1016/j.jvir.2009.12.398] [Medline: 20346880] 
4. Swan MC, Oliver DW, Cassell OCS, Coleman DJ, Williams N, Morritt DG, et al. Randomized controlled trial of fibrin sealant to reduce postoperative drainage following elective lymph node dissection. Br J Surg 2011 Jul;98(7):918-924. [doi: 10.1002/bjs.7462] [Medline: 21456091]

5. Pessa ME, Hawkins IF, Vogel SB. The treatment of acute cholangitis. Percutaneous transhepatic biliary drainage before definitive therapy. Ann Surg 1987 Apr;205(4):389-392 [FREE Full text] [doi: 10.1097/00000658-198704000-00008] [Medline: 3566375]

6. Sartelli M, Viale P, Catena F, Ansaloni L, Moore E, Malangoni M, et al. 2013 WSES guidelines for management of intra-abdominal infections. World J Emerg Surg 2013 Jan 08;8(1):3 [FREE Full text] [doi: 10.1186/1749-7922-8-3] [Medline: 23294512]

7. Miura F, Okamoto K, Takada T, Strasberg SM, Asbun HJ, Pitt HA, et al. Tokyo Guidelines 2018: initial management of acute biliary infection and flowchart for acute cholangitis. J Hepatobiliary Pancreat Sci 2018 Jan;25(1):31-40 [FREE Full text] [doi: 10.1002/jhbp.509] [Medline: 28941329]

8. Kim KH, Sung CK, Park BK, Kim WK, Oh CW, Kim KS. Percutaneous gallbladder drainage for delayed laparoscopic cholecystectomy in patients with acute cholecystitis. Am J Surg 2000 Feb;179(2):111-113 [FREE Full text] [doi: 10.1016/s0002-9610(00)00247-6] [Medline: 10773145]

9. Bickel A, Hoffman RS, Loberant N, Weiss M, Eitan A. Timing of percutaneous cholecystostomy affects conversion rate of delayed laparoscopic cholecystectomy for severe acute cholecystitis. Surg Endosc 2016 Mar;30(3):1028-1033 [FREE Full text] [doi: 10.1007/s00464-015-4290-y] [Medline: 26139479]

10. Campbell NL, Zhan J, Tu W, Weber Z, Ambeuhl R, McKay C, et al. Self-Reported Medication Adherence Barriers Among Ambulatory Older Adults with Mild Cognitive Impairment. Pharmacotherapy 2016 Feb;36(2):196-202 [FREE Full text] [doi: 10.1002/phar.1702] [Medline: 26890914]

11. Wildenbos GA, Peute L, Jaspers M. Aging barriers influencing mobile health usability for older adults: A literature based framework (MOLD-US). Int J Med Inform 2018 Jun;114:66-75. [doi: 10.1016/j.ijmedinf.2018.03.012] [Medline: 29673606]

12. Pettee GK, McClain JJ, Schmid KK, Storti KL, Ainsworth BE. Reliability and convergent validity of the past-week Modifiable Activity Questionnaire. Public Health Nutr 2011 Mar;14(3):435-442. [doi: 10.1017/S1368980010002612] [Medline: 20843404]

13. McMillan MT, Fisher WE, Van Buren G, McElhany A, Bloomston M, Hughes SJ, et al. The value of drains as a fistula mitigation strategy for pancreatoduodenectomy: something for everyone? Results of a randomized prospective multi-institutional study. J Gastrointest Surg 2015 Jan;19(1):21-30; discussion 30 [FREE Full text] [doi: 10.1007/s11605-014-2640-z] [Medline: 25183409]

14. Wiggers JK, Coelen RJS, Rauws EAJ, van Delden OM, van Eijck CHJ, de Jonge J, et al. Preoperative endoscopic versus percutaneous transhepatic biliary drainage in potentially resectable perihilar cholangiocarcinoma (DRAINAGE trial): design and rationale of a randomized controlled trial. BMC Gastroenterol 2015 Feb 14;15:20 [FREE Full text] [doi:

10.1186/s12876-015-0251-0] [Medline: 25887103]

15. Arean PA, Hallgren KA, Jordan JT, Gazzaley A, Atkins DC, Heagerty PJ, et al. The Use and Effectiveness of Mobile Apps for Depression: Results From a Fully Remote Clinical Trial. J Med Internet Res 2016 Dec 20;18(12):e330 [FREE Full text] [doi: 10.2196/jmir.6482] [Medline: 27998876]

16. Goyal S, Lewis G, Yu C, Rotondi M, Seto E, Cafazzo JA. Evaluation of a Behavioral Mobile Phone App Intervention for the Self-Management of Type 2 Diabetes: Randomized Controlled Trial Protocol. JMIR Res Protoc 2016 Aug 19;5(3):e174 [FREE Full text] [doi: 10.2196/resprot.5959] [Medline: 27542325]

17. Fiordelli M, Diviani N, Schulz PJ. Mapping mHealth research: a decade of evolution. J Med Internet Res 2013;15(5):e95 [FREE Full text] [doi: 10.2196/jmir.2430] [Medline: 23697600]

18. Free C, Phillips G, Watson L, Galli L, Felix L, Edwards P, et al. The effectiveness of mobile-health technologies to improve health care service delivery processes: a systematic review and meta-analysis. PLoS Med 2013 Jan;10(1):e1001363 [FREE Full text] [doi: 10.1371/journal.pmed.1001363] [Medline: 23458994]

19. Kessel KA, Vogel MM, Kessel C, Bier H, Biedermann T, Friess H, et al. Mobile Health in Oncology: A Patient Survey About App-Assisted Cancer Care. JMIR Mhealth Uhealth 2017 Jun 14;5(6):e81 [FREE Full text] [doi: 10.2196/mhealth.7689] [Medline: 28615159]

20. Hung C, Yu J, Lin Y, Chen Y, Huang C, Lee J, et al. Mortality Benefit of a Fourth-Generation Synchronous Telehealth Program for the Management of Chronic Cardiovascular Disease: A Longitudinal Study. J Med Internet Res 2016 May 13;18(5):e102 [FREE Full text] [doi: 10.2196/jmir.5718] [Medline: 27177497]

21. Doocy S, Paik KE, Lyles E, Hei TH, Fahed Z, Winkler E, et al. Guidelines and mHealth to Improve Quality of Hypertension and Type 2 Diabetes Care for Vulnerable Populations in Lebanon: Longitudinal Cohort Study. JMIR Mhealth Uhealth 2017 Oct 18;5(10):e158 [FREE Full text] [doi: 10.2196/mhealth.7745] [Medline: 29046266]

22. Ahmed I, Ahmad NS, Ali S, Ali S, George A, Saleem DH, et al. Medication Adherence Apps: Review and Content Analysis. JMIR Mhealth Uhealth 2018 Mar 16;6(3):e62 [FREE Full text] [doi: 10.2196/mhealth.6432] [Medline: 29549075]

23. Machado SM, Wilson EH, Elliott JO, Jordan K. Impact of a telemedicine eICU cart on sepsis management in a community hospital emergency department. J Telemed Telecare 2018 Apr;24(3):202-208. [doi: 10.1177/1357633X17691862] [Medline: 29278979] 
24. Wu J, Ho T, Chang Y, Hsu C, Tsai CJ, Lai F, et al. Wearable-Based Mobile Health App in Gastric Cancer Patients for Postoperative Physical Activity Monitoring: Focus Group Study. JMIR Mhealth Uhealth 2019 Apr 23;7(4):e11989 [FREE Full text] [doi: 10.2196/11989] [Medline: $\underline{31012858}$ ]

25. Kummerow BK, Oyefule OO, Phillips SE, Baucom RB, Holzman MD, Sharp KW, et al. Postoperative Care Using a Secure Online Patient Portal: Changing the (Inter)Face of General Surgery. J Am Coll Surg 2015 Dec;221(6):1057-1066. [doi: 10.1016/i.jamcollsurg.2015.08.429] [Medline: 26453260]

26. Eisenberg D, Hwa K, Wren SM. Telephone follow-up by a midlevel provider after laparoscopic inguinal hernia repair instead of face-to-face clinic visit. JSLS 2015;19(1):e2014.00205 [FREE Full text] [doi: 10.4293/JSLS.2014.00205] [Medline: 25848178]

27. Canon S, Shera A, Patel A, Zamilpa I, Paddack J, Fisher PL, et al. A pilot study of telemedicine for post-operative urological care in children. J Telemed Telecare 2014 Dec;20(8):427-430 [FREE Full text] [doi: 10.1177/1357633X14555610] [Medline: 25316038]

28. Sanger PC, Hartzler A, Han SM, Armstrong CAL, Stewart MR, Lordon RJ, et al. Patient perspectives on post-discharge surgical site infections: towards a patient-centered mobile health solution. PLoS One 2014;9(12):e114016 [FREE Full text] [doi: 10.1371/journal.pone.0114016] [Medline: 25436912]

29. Sanger PC, Hartzler A, Lordon RJ, Armstrong CA, Lober WB, Evans HL, et al. A patient-centered system in a provider-centered world: challenges of incorporating post-discharge wound data into practice. J Am Med Inform Assoc 2016 May;23(3):514-525. [doi: 10.1093/jamia/ocv183] [Medline: 26977103]

30. Bangor A, Kortum P, Miller J. Determining What Individual SUS Scores Mean: Adding an Adjective Rating Scale. Journal of Usability Studies 2009;4(3):114-123 [FREE Full text]

31. Meyer N, Kerz M, Folarin A, Joyce DW, Jackson R, Karr C, et al. Capturing Rest-Activity Profiles in Schizophrenia Using Wearable and Mobile Technologies: Development, Implementation, Feasibility, and Acceptability of a Remote Monitoring Platform. JMIR Mhealth Uhealth 2018 Oct 30;6(10):e188 [FREE Full text] [doi: 10.2196/mhealth.8292] [Medline: 30377146]

32. Arostegui I, Legarreta MJ, Barrio I, Esteban C, Garcia-Gutierrez S, Aguirre U, IRYSS-COPD Group. A Computer Application to Predict Adverse Events in the Short-Term Evolution of Patients With Exacerbation of Chronic Obstructive Pulmonary Disease. JMIR Med Inform 2019 Apr 17;7(2):e10773 [FREE Full text] [doi: 10.2196/10773] [Medline: 30994471]

33. Yongping L, Juan Z, Zhou P, Yongfeng Z, Liu W, Shi Y. Evaluation of the Quadri-Planes Method in Computer-Aided Diagnosis of Breast Lesions by Ultrasonography: Prospective Single-Center Study. JMIR Med Inform 2020 May 05;8(5):e18251 [FREE Full text] [doi: 10.2196/18251] [Medline: $\underline{32369039}$ ]

34. Dittrich F, Beck S, Harren AK, Reinecke F, Serong S, Jung J, et al. Analysis of Secure Apps for Daily Clinical Use by German Orthopedic Surgeons: Searching for the "Needle in a Haystack". JMIR Mhealth Uhealth 2020 May 07;8(5):e17085 [FREE Full text] [doi: 10.2196/17085] [Medline: 32379054]

35. Hwa K, Wren SM. Telehealth follow-up in lieu of postoperative clinic visit for ambulatory surgery: results of a pilot program. JAMA Surg 2013 Sep;148(9):823-827 [FREE Full text] [doi: 10.1001/jamasurg.2013.2672] [Medline: 23842982]

36. Gurjar SV, Kulkarni D, Khawaja HT. Outpatient general surgical follow-up: are we using this resource effectively? Int J Surg 2009 Feb;7(1):62-65 [FREE Full text] [doi: 10.1016/j.ijsu.2008.10.014] [Medline: 19095510]

37. Rao R, Shukla BM, Saint-Cyr M, Rao M, Teotia SS. Take two and text me in the morning: optimizing clinical time with a short messaging system. Plast Reconstr Surg 2012 Jul;130(1):44-49. [doi: 10.1097/PRS.0b013e3182547d63] [Medline: 22743872]

38. Wiseman JT, Fernandes-Taylor S, Barnes ML, Tomsejova A, Saunders RS, Kent KC. Conceptualizing smartphone use in outpatient wound assessment: patients' and caregivers' willingness to use technology. J Surg Res 2015 Sep;198(1):245-251. [doi: 10.1016/j.jss.2015.05.011] [Medline: 26025626]

39. Chen DW, Davis RW, Balentine CJ, Scott AR, Gao Y, Tapia NM, et al. Utility of routine postoperative visit after appendectomy and cholecystectomy with evaluation of mobile technology access in an urban safety net population. J Surg Res 2014 Aug;190(2):478-483. [doi: 10.1016/j.jss.2014.04.028] [Medline: 24880202]

40. Wiseman JT, Guzman AM, Fernandes-Taylor S, Engelbert TL, Saunders RS, Kent KC. General and vascular surgery readmissions: a systematic review. J Am Coll Surg 2014 Sep;219(3):552-69.e2 [FREE Full text] [doi: 10.1016/j.jamcollsurg.2014.05.007] [Medline: 25067801]

41. Goldstein MM, Thorpe Jane H. The First Anniversary of the Health Information Technology for Economic and Clinical Health (HITECH) Act: the regulatory outlook for implementation. Perspect Health Inf Manag 2010 Sep 01;7:1c [FREE Full text] [Medline: 20808607]

42. Scott AR, Alore EA, Naik AD, Berger DH, Suliburk JW. Mixed-Methods Analysis of Factors Impacting Use of a Postoperative mHealth App. JMIR Mhealth Uhealth 2017 Feb 08;5(2):e11 [FREE Full text] [doi: 10.2196/mhealth.6728] [Medline: 28179215]

43. Zhu Z, Zhang H, Li Y, Meng X, Jiao Y, Qin Y, et al. Establishment of a New Platform for the Management of Patients After Cardiac Surgery: Descriptive Study. JMIR Med Inform 2019 Apr 01;7(2):e13123 [FREE Full text] [doi: 10.2196/13123] [Medline: $\underline{30932865]}$ 
44. Dahlberg K, Jaensson M, Nilsson U, Eriksson M, Odencrants S. Holding It Together-Patients' Perspectives on Postoperative Recovery When Using an e-Assessed Follow-Up: Qualitative Study. JMIR Mhealth Uhealth 2018 May 25;6(5):e10387 [FREE Full text] [doi: 10.2196/10387] [Medline: 29802094]

45. Jaensson M, Dahlberg K, Eriksson M, Grönlund , Nilsson U. The Development of the Recovery Assessments by Phone Points (RAPP): A Mobile Phone App for Postoperative Recovery Monitoring and Assessment. JMIR Mhealth Uhealth 2015;3(3):e86 [FREE Full text] [doi: 10.2196/mhealth.4649] [Medline: 26362403]

46. Sylvia LG, Bernstein EE, Hubbard JL, Keating L, Anderson EJ. Practical guide to measuring physical activity. J Acad Nutr Diet 2014 Feb;114(2):199-208 [FREE Full text] [doi: 10.1016/j.jand.2013.09.018] [Medline: 24290836]

47. Jacobs DR, Ainsworth BE, Hartman TJ, Leon AS. A simultaneous evaluation of 10 commonly used physical activity questionnaires. Med Sci Sports Exerc 1993 Jan;25(1):81-91 [FREE Full text] [doi: 10.1249/00005768-199301000-00012] [Medline: $\underline{8423759}$ ]

48. Shephard RJ. Limits to the measurement of habitual physical activity by questionnaires. Br J Sports Med 2003 Jun;37(3):197-206; discussion 206 [FREE Full text] [doi: 10.1136/bjsm.37.3.197] [Medline: 12782543]

49. Quinn CC, Staub S, Barr E, Gruber-Baldini A. Mobile Support for Older Adults and Their Caregivers: Dyad Usability Study. JMIR Aging 2019 May 23;2(1):e12276 [FREE Full text] [doi: 10.2196/12276] [Medline: 31518271]

50. Or CK, Liu K, So MKP, Cheung B, Yam LYC, Tiwari A, et al. Improving Self-Care in Patients With Coexisting Type 2 Diabetes and Hypertension by Technological Surrogate Nursing: Randomized Controlled Trial. J Med Internet Res 2020 Mar 27;22(3):e16769 [FREE Full text] [doi: 10.2196/16769] [Medline: 32217498]

51. Rosner BI, Gottlieb M, Anderson WN. Accuracy of Internet-Based Patient Self-Report of Postdischarge Health Care Utilization and Complications Following Orthopedic Procedures: Observational Cohort Study. J Med Internet Res 2018 Jul 20;20(7):e10405 [FREE Full text] [doi: 10.2196/10405] [Medline: 30030212]

52. Coons SJ, Gwaltney CJ, Hays RD, Lundy JJ, Sloan JA, Revicki DA, et al. Recommendations on evidence needed to support measurement equivalence between electronic and paper-based patient-reported outcome (PRO) measures: ISPOR ePRO Good Research Practices Task Force report. Value Health 2009 Jun;12(4):419-429. [doi: 10.1111/j.1524-4733.2008.00470.x] [Medline: 19900250]

53. Kessel KA, Vogel MM, Schmidt-Graf F, Combs SE. Mobile Apps in Oncology: A Survey on Health Care Professionals' Attitude Toward Telemedicine, mHealth, and Oncological Apps. J Med Internet Res 2016 Nov 24;18(11):e312 [FREE Full text] [doi: 10.2196/jmir.6399] [Medline: 27884810]

54. Gunter R, Fernandes-Taylor S, Mahnke A, Awoyinka L, Schroeder C, Wiseman J, et al. Evaluating Patient Usability of an Image-Based Mobile Health Platform for Postoperative Wound Monitoring. JMIR Mhealth Uhealth 2016 Sep 28;4(3):e113 [FREE Full text] [doi: 10.2196/mhealth.6023] [Medline: 27683059]

55. Fernandes-Taylor S, Gunter RL, Bennett KM, Awoyinka L, Rahman S, Greenberg CC, et al. Feasibility of Implementing a Patient-Centered Postoperative Wound Monitoring Program Using Smartphone Images: A Pilot Protocol. JMIR Res Protoc 2017 Feb 22;6(2):e26 [FREE Full text] [doi: 10.2196/resprot.6819] [Medline: 28228369]

56. Gunter RL, Fernandes-Taylor S, Rahman S, Awoyinka L, Bennett KM, Weber SM, et al. Feasibility of an Image-Based Mobile Health Protocol for Postoperative Wound Monitoring. J Am Coll Surg 2018 Mar;226(3):277-286. [doi: 10.1016/j.jamcollsurg.2017.12.013] [Medline: 29366555]

57. Lalloo C, Shah U, Birnie KA, Davies-Chalmers C, Rivera J, Stinson J, et al. Commercially Available Smartphone Apps to Support Postoperative Pain Self-Management: Scoping Review. JMIR Mhealth Uhealth 2017 Oct 23;5(10):e162 [FREE Full text] [doi: 10.2196/mhealth.8230] [Medline: 29061558]

58. Symer MM, Abelson JS, Milsom J, McClure B, Yeo HL. A Mobile Health Application to Track Patients After Gastrointestinal Surgery: Results from a Pilot Study. J Gastrointest Surg 2017 Sep;21(9):1500-1505. [doi: 10.1007/s11605-017-3482-2] [Medline: 28685388]
Abbreviations
eHealth: electronic health
mHealth: mobile health
WHO: World Health Organization 
Edited by G Eysenbach; submitted 04.01.20; peer-reviewed by R Ciptaningtyas, A Zink, CS Hung, R Kaczmarczyk; comments to author 12.06.20; revised version received 16.07.20; accepted 19.07.20; published 28.08.20

Please cite as:

Liao CH, Wu YT, Cheng CT, Ooyang CH, Kang SC, Fu CY, Hsu YP, Hsieh CH, Chen CC

An Image-Based Mobile Health App for Postdrainage Monitoring: Usability Study

$J$ Med Internet Res 2020;22(8):e17686

URL: http://www.jmir.org/2020/8/e17686/

doi: $10.2196 / 17686$

PMID: $\underline{32857060}$

(CChien-Hung Liao, Yu-Tung Wu, Chi-Tung Cheng, Chun-Hsiang Ooyang, Shih-Ching Kang, Chih-Yuan Fu, Yu-Pao Hsu, Chi-Hsun Hsieh, Chih-Chi Chen. Originally published in the Journal of Medical Internet Research (http://www.jmir.org), 28.08.2020. This is an open-access article distributed under the terms of the Creative Commons Attribution License (https://creativecommons.org/licenses/by/4.0/), which permits unrestricted use, distribution, and reproduction in any medium, provided the original work, first published in the Journal of Medical Internet Research, is properly cited. The complete bibliographic information, a link to the original publication on http://www.jmir.org/, as well as this copyright and license information must be included. 